VOL. 5 NO. 2 Halaman 80-86

$P$ - ISSN : 2580-6173

E-ISSN : 2548-6144

Available Online http://ojs.itekes-bali.ac.id/index.php/jrkn/index

\title{
HUBUNGAN POLA MAKAN DENGAN DERAJAT HIPERTENSI PADA LANSIA DI PUSKESMAS UBUD I
}

\section{(The Correlation Between Dietary Habit and Hypertension Level In Elderly at Public Health Center Ubud I) Ida Ayu Manik Damayanti $\left.\left.\left.{ }^{*}\right),{ }^{* *}\right),{ }^{* * *}\right),{ }^{* * *}$ Institut Teknologi dan Kesehatan Bali
Email: dellaclarisa7@gmail.com \\ Gusti Ayu Della Clarisa ${ }^{*}$, Kadek Nuryanto ${ }^{* *}$, I Putu Gde Yudara Sandra $P^{* * *}$,}

\begin{abstract}
ABSTRAK
Tujuan : Penelitian ini bertujuan untuk mengetahui hubungan pola makan dengan derajat hipertensi pada lansia di Puskesmas Ubud I.

Metode : Desain penelitian analitik korelatif dengan pendekatan cross -sectional. Sampel yang digunakan berjumlah 84 responden yang dipilih dengan teknik purposive sampling. Pengumpulan data menggunakan kuesioner dan pengukuran tekanan darah, data dianalisis menggunakan Spearman's Rho Correlation.

Hasil : Pola makan merupakan perilaku yang dapat mempengaruhi asupan gizi sehingga akan mempengaruhi kesehatan individu seperti hipertensi. Pola makan yang sehat berhubungan dengan hipertensi yang mana dilakukan dengan memperhatikan asupan makanan yang dikonsumsi serta mengkonsumsi makanan yang sehat. Hasil penelitian menunjukkan sebagaian besar memiliki pola makan responden dengan kategori cukup $(64,3 \%)$, pola makan baik $(32,1 \%)$ dan pola makan kurang $(3,6 \%)$. Pada kategori hipertensi diketahui yang mengalami hipertensi Grade I $(56,0 \%)$, Grade II $(34,5 \%)$ dan Grade III $(9,5 \%)$. Terdapat hubungan antara pola makan dengan derajat hipertensi pada lansia di Puskesmas Ubud I dengan nilai $r=0,282, p<0,009$.

Kesimpulan : Pola makan memiliki hubungan yang signifikan dengan derajat hipertensi pada lansia di Puskesmas Ubud I. Bagi lansia hipertensi agar mengatur serta menjaga pola makannya menjadi lebih baik lagi seperti halnya tidak mengkonsumsi atau mengurangi makanan yang dapat menyebabkan peningkatan tekanan darah.
\end{abstract}

Kata Kunci: pola makan, hipertensi, lansia

\section{ABSTRACT}

Aim : To determine the correlation between dietary habit and hypertension level in elderly at public health center Ubud I.

Method : This study employed correlative analytic design with cross-sectional approach. There were 84 respondents selected as sample of this study through purposive sampling technique. The data were collected by using questionnaire and analyzed through Spearman's Rho Correlation test.

Resul t: Dietary habit is a behavior that can affect nutritional intake so that it will affect individual health such as hypertension. A healthy dietary habit is associated with hypertension which is carried out by paying attention to the intake of food consumed and consuming healthy foods. The results showed that most of the respondents had a moderate dietary habit $(64.3 \%)$, a good dietary habit $(32.1 \%)$ and a poor dietary habit $(3.6 \%)$. In the hypertension category, it is known that hypertension level on Grade I (56.0\%), Grade II (34.5\%) and Grade III (9.5\%). There is a relationship between dietary habit and the hypertension level in the elderly at the public health center Ubud I , $r=0.282, p<0.009$. 
Conclusion: Dietary habit has a significant relationship with the degree of hypertension in the elderly at the Ubud I Health Center. Elderly with hypertension is expected to organize and maintain a better dietary habit as well as not to consume or reduce food that causes the increase of blood pressure.

Keywords: dietary habit, hypertension, elderly

\section{LATAR BELAKANG}

Seiring dengan peningkatan usia, lansia selalu dihadapkan dengan banyak masalah perubahan yang kompleks dalam pola kesehatan dan pola penyakit yang mengakibatkan transisi epidemiologi menjadi penyakit tidak menular. Perubahan ini akan berpengaruh terhadap jumlah dan jenis pelayanan kesehatan yang dibutuhkan masyarakat nantinya (Riskesdas, 2013). Salah satu masalah kesehatan yang dihadapi lansia adalah hipertensi. Hipertensi atau yang dikenal dengan peningkatan tekanan darah tinggi dimana suatu kondisi tekanan pada pembuluh darah meningkat secara persisten (WHO, 2018).

WHO menyebutkan batasan umur penduduk lanjut usia meliputi middle age (45 -59 tahun), elderly (60-70 tahun), old (75-90 tahun), very old (diatas 90 tahun) (Siyoto, 2016). Lansia adalah kelompok orang/umur yang telah memasuki tahapan akhir dari fase kehidupannya. Menurut WHO dan the International Society of Hypertension (2018), saat ini terdapat 600 juta penduduk penderita hipertensi di seluruh dunia, dan 3 juta di antaranya meninggal dunia setiap tahunnya (WHO, 2018). American Hearth Association (AHA) tahun 2014 melaporkan penderita hipertensi di Amerika mencapai angka 74,5 juta jiwa, dan hampir sekitar 95\% kasus tidak diketahui masalahnya. Berdasarkan data WHO, di seluruh dunia sekitar 972 juta orang dengan persentase sebesar $26,4 \%$ orang di seluruh dunia mengidap hipertensi, angka ini kemungkinan akan meningkat menjadi $29,2 \%$ di tahun 2025. Jumlah keseluruhan pengidap hipertensi di dunia sebanyak 972 juta pengidap hipertensi, 333 juta berada di negara maju dan 639 sisanya berada di negara berkembang, termasuk Indonesia. Di Indonesia hipertensi merupakan tantangan besar yang terjadi sampai saat ini.

Prevalensi hipertensi lansia di Indonesia dilaporkan mengalami peningkatan. Riset Kesehatan Dasar (Riskesdas) tahun 2013 melaporkan bahwa kasus hipertensi mengalami peningkatan sejumlah $2,4 \%$ dari $31,7 \%$ pada tahun 2013 menjadi $34,1 \%$ pada tahun 2018. Sebagian besar kasus hipertensi didapatkan pada usia lanjut sebanyak 254.401 jiwa (Riskesdas, 2018). Data Dinas Kesehatan (Dinkes) Provinsi Bali tahun 2018 menyebutkan bahwa prevalensi hipertensi di Provinsi Bali mengalami peningkatan sebesar 10,3\% yang mana pada tahun 2018 mencapai $31,1 \%$. Prevalensi penduduk dengan hipertensi sebesar $34,11 \%$, prevalensi hipertensi pada perempuan $(36,85 \%)$ lebih tinggi dibanding dengan laki-laki $(31,34 \%)$. Salah satu kabupaten di Bali dengan penderita hipertensi terbanyak adalah Kabupaten Gianyar. Data Profil Kesehatan Kabupaten Gianyar Tahun 2018 menyebutkan hipertensi berada pada peringkat ke 2 dengan jumlah kunjungan tahun 2018 absolut sebanyak 6,489 kasus $(13,97 \%)$. Adapun hasil pengukuran/deteksi dini hipertensi untuk tahun 2018 yang mana jumlah sasaran sebanyak 284.744 penduduk $>18$ tahun. Penyakit hipertensi mencapai 154.989 di UPT Kesmas.

Penatalaksanaan hipertensi dapat dilakukan dengan dua cara yaitu secara farmakologi menggunakan obat-obatan dan non farmakologi dengan cara modifikasi gaya hidup termasuk asupan makanan (Buheli \& Usman, 2019). Faktor risiko yang mempengaruhi hipertensi yang dapat diubah yaitu kegemukan (obesitas), merokok, kurang aktivitas fisik, konsumsi garam berlebihan, displidemia, konsumsi alkohol berlebihan dan psikososial stress (Kemenkes, 2013). Salah satu faktor risiko yang menyebabkan meningkatnya terjadinya hipertensi yaitu kebiasaan gaya hidup serta pola makan seperti: mengkonsumsi alkohol, mengkonsumsi makanan dengan kadar garam berlebihan, minuman berkafein, makanan berkolesterol tinggi. Menurut (Malonda, Lucia \& Retno, 2018) mengatakan faktor yang paling berpengaruh terhadap hipertensi yaitu pola makan yangmana lansia yang mengkonsumsi asupan lemak yang paling besar pengaruhnya terhadap hipertensi, lansia yang mengkonsumsi lemak lebih dari $25 \%$ total kalori per hari mempunyai risiko 3,303 kali lebih besar untuk menderita hipertensi. Di Indonesia terdapat pergeseran pola makan, yang mengarah pada makanan cepat saji dan diawetkan yang dapat kita ketahui mengandung garam tinggi, lemak jenuh, dan rendah serat mulai menjamur terutama di kota-kota besar di Indonesia.

Jurnal Riset Kesehatan Nasional hal. 81 
Menurut penelitian (Sunarto, 2018) pola makan merupakan perilaku yang dapat mempengaruhi asupan gizi sehingga akan mempengaruhi kesehatan individu. Pola makan yang sehat berhubungan dengan hipertensi yangmana dengan memperhatikan asupan makanan yang dikonsumsi serta mengkonsumsi makanan yang sehat seperti sayur dan buah (Sunarto, 2018). Menurut (Ilham, Harleni \& Siska, 2019) mengatakan pola makan yang umum dikonsumsi oleh lansia yaitu sering mengkonsumsi makanan yang tinggi garam, sering menggunakan penyedap rasa dan santan pada saat memasak, sering mengkonsumsi gorengan sebagai cemilan serta mengkonsumsi teh dan telur sehingga menimbulkan tekanan darah tidak terkontrol dengan baik pada lansia.

Pada penelitian (Sunarto, 2018) menyatakan hasil penelitian adanya pengaruh pola makan terhadap kejadian hipertensi di wilayah kerja Puskesmas Dungaliyo Kabupaten Gorontalo, pola makan baik sebanyak $(63,6 \%)$ dan pola makan buruk sebanyak (36,4\%). Berdasarkan penelitian (Afniwati, 2019) menyatakan hasil penelitian bahwa adanya hubungan pola makan dengan kejadian hipertensi, sebanyak $(41,4 \%)$ pola makan baik, $(22,0 \%)$ pola makan kurang. Sementara itu berdasarkan penelitian (Ogis,2018) menyatakan hasil penelitian ada hubungan bermakna antara pola makan dengan kejadian hipertensi pada lansia yangmana pada penelitian ini dikatakan bahwa pola makan lansia yang ada di Dusun Blokseger didominasi dengan pola makan buruk sehingga hal tersebut dapat menyebabkan peningkatan darah tinggi pada lansia dengan presentase pola makan buruk sebesar $60 \%$, pola makan baik $40 \%$. Berbanding terbalik dengan penelitian (Oktoruddin Harun, 2018) menyatakan hasil penelitian tidak adanya hubungan antara pola makan dengan kejadian hipertensi, sebanyak 55,9\% mengalami hipertensi dengan kategori pola makan sering 95,6\%.

Berdasarkan data yang diperoleh, masih banyak yang mengalami kejadian hipertensi dan mengalami peningkatan penderita setiap tahunnya. Selain itu, hasil penelitian yang sebelumnya diketahui hasil yang berbeda dan bertolak belakang sehingga perlu dilakukan penelitian kembali untuk mengurangi kasus hipertensi dengan mengatur dan menjaga pola makan agar tekanan darah tetap dalam keadaan normal. Berdasarkan uraian tersebut peneliti tertarik untuk melakukan penelitian mengenai Hubungan Pola Makan Dengan Derajat Hipertensi Pada Lansia Di Puskesmas Ubud I.

\section{METODE}

Desain penelitian yang digunakan pada penelitian ini adalah analitik korelasi dengan metode pendekatan cross-sectional. Populasi dalam penelitian ini adalah lansia yang mengunjungi Puskesmas Ubud I. Teknik sampling yang digunakan dalam penelitian ini menggunakan metode purposive sampling, yaitu sebanyak 84 orang. Purposive sampling adalah sampel yang dipilih melalui penetapan kriteria tertentu. Alat pengumpulan data dalam penelitian ini yaitu menggunakan kuesioner pola makan yang sudah dilakukan uji validitas sebelumnya dan pengukuran tekanan darah. Analisa data dalam penelitian ini menggunakan Uji Spearman Rank (Rho).

\section{HASIL \\ Karakteristik Responden}

Tabel 1. Distribusi Frekuensi berdasarkan Karakteristik Responden Lansia Di Puskesmas Ubud I ( $\mathrm{n}=84)$

\begin{tabular}{|c|c|c|}
\hline Karakteristik & (n) & $(\%)$ \\
\hline \multicolumn{3}{|l|}{ Umur } \\
\hline $60-70$ & 54 & 64 \\
\hline $71-80$ & 28 & 33 \\
\hline$>80$ & 2 & 3 \\
\hline \multicolumn{3}{|l|}{ Jenis Kelamin } \\
\hline Laki-laki & 39 & 46.4 \\
\hline Perempuan & 45 & 53.6 \\
\hline \multicolumn{3}{|l|}{$\begin{array}{l}\text { Pendidikan Ter- } \\
\text { akhir }\end{array}$} \\
\hline $\mathrm{SD}$ & 6 & 7.1 \\
\hline SMP & 17 & 20.2 \\
\hline SMA & 30 & 35.7 \\
\hline Perguruan & 23 & 27.4 \\
\hline Tinggi & & \\
\hline Tidak Sekolah & 8 & 9.5 \\
\hline \multicolumn{3}{|l|}{$\begin{array}{l}\text { Status Perkawi- } \\
\text { nan }\end{array}$} \\
\hline Menikah & 83 & 98.8 \\
\hline Duda/Janda & 1 & 1.2 \\
\hline \multicolumn{3}{|l|}{ Pekerjaan } \\
\hline PNS/Pensiun & 14 & 16.7 \\
\hline Pegawai & 20 & 23.8 \\
\hline Swasta & & \\
\hline Wiraswasta & 30 & 35.7 \\
\hline Tidak Bekerja & 18 & 21.4 \\
\hline Lainnya & 2 & 2.4 \\
\hline \multicolumn{3}{|l|}{ Berat Badan } \\
\hline $40-60$ & 60 & 71 \\
\hline$>60$ & 24 & 29 \\
\hline
\end{tabular}

Jurnal Riset Kesehatan Nasional hal. 82 
Berdasarkan Tabel 1 menunjukkan bahwa dari 84 responden, karakteristik responden berdasarkan umur, semua responden berumur $>60$ tahun, yang terbanyak adalah responden yang berumur 61 sebanyak 10 responden $(11,9 \%)$. Berdasarkan jenis kelamin, perempuan lebih banyak daripada laki-laki yaitu sebanyak 45 responden $(53,6 \%)$. Berdasarkan pendidikan terakhir, yang terbanyak adalah pendidikan terakhir SMA yaitu sebanyak 30 responden $(35,7 \%)$. Berdasarkan status perkawinan, yang terbanyak adalah status menikah yaitu sebanyak 83 responden $(98,8 \%)$. Berdasarkan pekerjaan, yang terbanyak adalah pekerjaan sebagai wiraswasta yaitu sebanyak 30 responden $(35,7 \%)$. Sedangkan berdasarkan berat badan, yang terbanyak adalah berat badan 56 sebanyak 6 responden $(7,1 \%)$ dan berat badan 65 sebanyak 6 responden $(7,1 \%)$.

\section{Hasil Penelitian berdasarkan Variabel Analisa Univariate}

Tabel 2. Distribusi Frekuensi Pola Makan Pada Lansia Hipertensi Di Puskesmas Ubud I $(n=84)$

Pola makan cukup pada lansia disebabkan karena kurangnya kepatuhan diet lansia. Hal tersebut ditunjukan dengan sebanyak 45 responden $(53,6 \%)$ menjawab kadang-kadang

\begin{tabular}{llll}
\hline No & $\begin{array}{l}\text { Pola } \\
\text { Makan } \\
\text { Lansia }\end{array}$ & $\begin{array}{l}\text { Frekuensi } \\
\text { (f) }\end{array}$ & $\begin{array}{l}\text { Persentase } \\
(\%)\end{array}$ \\
\hline 1 & Baik & 27 & 32,1 \\
2 & Cukup & 54 & 64,3 \\
3 & Kurang & 3 & 3,6 \\
& Jumlah & 84 & 100,0 \\
\hline
\end{tabular}

pada pernyataan "Mengkonsumsi daging merah". Pada pernyataan "Mengkonsumsi makanan laut" sebanyak 39 responden $(46,4 \%)$ menjawab kadang-kadang yangmana makanan berlemak berhubungan dengan peningkatan berat badan dan peningkatan kadar lemak dalam darah yang dapat memperburuk keadaan penderita hipertensi.

Berdasarkan Tabel 2 dapat dilihat bahwa dari 84 responden sebagaian besar memiliki pola makan yang cukup sebanyak 54 responden $(64,3 \%)$.

Tabel 3. Distribusi Frekuensi Kategori Derajat Hipertensi Pada Lansia Di Puskesmas Ubud I $(\mathrm{n}=84)$

Ada beberapa faktor yang mempengaruhi derajat hipertensi salah satunya adalah pola makan seperti mengkonsumsi daging merah, makanan laut, olahan ikan asin dan asupan kafein berlebihan. Mengkonsumsi daging merah, makanan laut

\begin{tabular}{llll}
\hline No & $\begin{array}{l}\text { Derajat } \\
\text { Hipertensi }\end{array}$ & $\begin{array}{l}\text { Frekuensi } \\
\text { (f) }\end{array}$ & $\begin{array}{l}\text { Persen- } \\
\text { tase (\%) }\end{array}$ \\
\hline 1 & $\begin{array}{l}\text { Hipertensi } \\
\text { Grade I }\end{array}$ & 47 & 56.0 \\
2 & $\begin{array}{l}\text { Hipertensi } \\
\text { Grade II }\end{array}$ & 29 & 34.5 \\
3 & Hipertensi & 8 & 9.5 \\
& Grade III & & \\
& Jumlah & 84 & 100,0 \\
\hline
\end{tabular}

dapat meningkatkan kadar lemak dalam darah yang dapat memperburuk keadaan penderita hipertensi dan ketika penderita hipertensi mengkonsumsi olahan ikan asin dapat menyebabkan terjadinya ketidakseimbangan cairan dalam tubuh sedangkan jika mengkonsumsi kafein yang berlebihan dapat menyebabkan peningkatan tekanan darah (Berdamai, 2017).

Berdasarkan Tabel 3 dapat dilihat bahwa sebagian besar mengalami Hipertensi Grade I, yaitu sebanyak 47 responden $(56,0 \%)$.

\section{Analisa Bivariate}

Tabel 4. Hasil korelasi Spearman's rho pola makan dengan derajat hipertensi pada lansia di Puskesmas Ubud I ( $\mathrm{n}=84)$

Berdasarkan Tabel 4 menunjukan bahwa Pvalue $<0,009$ yang artinya bahwa nilai $p<0,05$, maka Ha diterima yang mana hasilnya menunjukan ada hubungan yang signifikan antara pola makan dengan derajat hipertensi pada lansia di Puskesmas Ubud I. Hubungan ini ditunjukan dengan kekuatan korelasi $(r=0,282)$ yang termasuk dalam kategori rendah $(0,20-0,399)$ dengan arah

\begin{tabular}{llll}
\hline & & $\begin{array}{l}\text { Derajat } \\
\text { Hiperten } \\
\text { si }\end{array}$ & $\begin{array}{l}\text { Pola } \\
\text { Makan }\end{array}$ \\
\hline $\begin{array}{l}\text { Derajat } \\
\text { Hiperten- }\end{array}$ & $\mathrm{r}$ & 1.000 & $.282^{* *}$ \\
& $\mathrm{p}$ & .009 \\
$\begin{array}{l}\text { Pola } \\
\text { Makan }\end{array}$ & $\mathrm{r}$ & $.282^{* *}$ & 1.000 \\
& $\mathrm{p}$ & .009 & \\
\hline
\end{tabular}


korelasi positif $(+)$ yang berarti peningkatan nilai pada pola makan sejalan dengan peningkatan pada derajat hipertensi, begitu juga sebaliknya. Hasil tersebut juga menunjukkan semakin tinggi peningkatan pola makan, derajat hipertensi lansia akan mengalami penurunan dan sebaliknya.

\section{PEMBAHASAN \\ Pola Makan Pada Lansia}

Pola makan adalah kebiasaan makan seseorang setiap hari dilihat dari jenis dan frekuensi makan, setiap individu membutuhkan pola makan yang sehat dan seimbang (Oktoruddin, 2018). Dari hasil penelitian menunjukan bahwa dari 84 responden sebanyak $27(32,1 \%)$ memiliki pola makan baik, sebanyak $54(64,3 \%)$ memiliki pola makan cukup dan sebanyak $3(3,6 \%)$ memiliki pola makan kurang. Sebagian responden memiliki pola makan cukup. Pola makan cukup pada lansia tersebut disebabkan karena kurangnya kepatuhan diet lansia.

Berdasarkan penelitian yang dilakukan (Ngurah dan Yahya, 2019) dengan judul "Gaya Hidup Penderita Hipertensi" dilihat dari hasil penelitian menyatakan pada pengaturan pola makan penderita hipertensi didapatkan gaya hidup responden tidak sehat. Hal ini dapat dilihat dari penderita hipertensi yang masih banyak mengkonsumsi makanan asin, sementara itu asupan natrium dan garam merupakan faktor risiko hipertensi oleh karena natrium merupakan salah satu mineral atau elektrolit yang berpengaruh terhadap tekanan darah.

Menurut penelitian yang dilakukan oleh (Pande, 2019) yang mengatakan bahwa agar tetap sehat dan bugar serta tekanan darah tetap stabil sebaiknya agar lansia hipertensi menjaga pola makanannya dengan mengkonsumsi jenis makanan seperti beras merah yang rendah gula dan kalori, gandum, kacang -kacangan dan sayuran hijau seperti kacang merah, buncis, brokoli, bayam, kol dan konsumsi makanan yang mengandung postasium tinggi seperti kentang, yogurt dan pisang serta mengkonsumsi suplemen omega 3 yang dipercaya dapat membantu menjaga elastisitas pembuluh darah.

\section{Derajat Hipertensi Pada Lansia}

Panduan British Hypertension Society menyatakan hipertensi adalah tekanan darah sistolik pada saat istirahat sama atau di atas $140 \mathrm{mmHg}$ sistolik dan diastolic $90 \mathrm{mmHg}$.
Menurut (Riskesdas, 2013) hipertensi adalah suatu keadaan ketika tekanan darah di pembuluh darah meningkat secara kronis hal tersebut dapat terjadi ketika jantung bekerja lebih keras memompa darah untuk memenuhi kebutuhan oksigen dan nutrisi tubuh, jika dibiarkan penyakit ini dapat mengganggu fungsi organ-organ lain, terutama organorgan vital seperti jantung dan ginjal. Berdasarkan penelitian yang telah dilakukan mengenai derajat hipertensi pada lansia didapatkan hasil bahwa sebagian besar lansia menderita hipertensi grade I yaitu sebanyak 47 responden $(56.0 \%)$, sisanya yaitu sebanyak 29 responden (34.5\%) menderita hipertensi grade II dan sebanyak 8 responden (9.5\%) menderita hipertensi grade III. Hal tersebut terjadi karena beberapa faktor salah satunya adalah pola makan seperti mengkonsumsi daging merah, makanan laut, olahan ikan asin dan asupan kafein berlebihan. Mengkonsumsi daging merah, makanan laut dapat meningkatkan kadar lemak dalam darah yang dapat memperburuk keadaan penderita hipertensi dan ketika penderita hipertensi mengkonsumsi olahan ikan asin dapat menyebabkan terjadinya ketidakseimbangan cairan dalam tubuh sedangkan jika mengkonsumsi kafein yang berlebihan dapat menyebabkan peningkatan tekanan darah (Berdamai, 2017).

Penelitian ini sejalan dengan penelitian yang dilakukan oleh (Subkhi, 2016) dengan judul "Hubungan Pola Makan Dengan Kejadian Hipertensi Pada Lansia Di Posyandu Mawar Desa Sangubanyu Kabupaten Purworejo". Dimana didapatkan hasil analisis menggunakan uji korelasi Rank Spearman, kemudian didapatkan hasil yaitu paling banyak responden mengalami hipertensi stadium 1 sebanyak 42 responden (56\%), sebanyak 26 responden $(34,7 \%)$ mengalami hipertensi stadium 2 dan yang paling sedikit hipertensi stadium 3 sebanyak 7 responden $(9,3 \%)$. Responden paling banyak mengalami kejadian hipertensi stadium 1 , hal ini terjadi karena beberapa faktor yaitu usia. hal ini dikuatkan oleh teori (Guyton, 2007) menyatakan tekanan darah cenderung rendah pada usia remaja dan mulai meningkat pada masa dewasa awal serta dapat meningkat lebih nyata selama masa pertumbuhan dan pematangan fisik di usia dewasa akhir sampai usia tua dikarenakan sistem sirkulasi darah akan terganggu, oleh karena itu pembuluh darah sering mengalami penyumbatan dinding pem-

Jurnal Riset Kesehatan Nasional hal. 84 
dinding pembuluh darah menjadi keras dan tebal serta berkurangnya elastisitas pembuluh darah sehingga menyebabkan tekanan darah menjadi tinggi.

\section{Hubungan Antara Pola Makan Dengan Derajat Hipertensi Pada Lansia}

Berdasarkan survey yang dilakukan oleh komnas lansia bahwa kondisi perilaku memakan makanan yang berisiko sangatlah menentukan peningkatan proporsi penderita gangguan kesehatan pada komunitas lansia seperti halnya mengkonsumsi makanan asin dan sering makan makanan berlemak dapat menyebabkan peningkatan tekanan darah (Budianto, 2014 dalam Ogis 2018). Dari hasil uji Spearman Rho antara pola makan dengan derajat hipertensi diperoleh hasil bahwa ada hubungan antara pola makan dengan derajat hipertensi pada lansia di Puskesmas Ubud I. Adanya hubungan pada kedua variabel ditunjukkan dari hasil uji korelasi Spearman Rho. Didapatkan nilai korelasi Pvalue $<0,009$ yang artinya bahwa nilai $p<0,05$, maka $\mathrm{Ha}$ diterima yang mana hasilnya menunjukan ada hubungan yang signifikan antara pola makan dengan derajat hipertensi pada lansia di Puskesmas Ubud I. Hubungan ini ditunjukan dengan kekuatan korelasi ( $\mathrm{r}=0,282)$ yang termasuk dalam kategori rendah $(0,20-0,399)$ yangmana dengan arah korelasi positif $(+)$ yang berarti peningkatan nilai pada pola makan sejalan dengan peningkatan pada derajat hipertensi, begitu juga sebaliknya. Hasil tersebut juga menunjukkan semakin tinggi peningkatan pola makan, derajat hipertensi lansia akan mengalami penurunan dan sebaliknya.

Penelitian ini sejalan dengan penelitian yang dilakukan oleh Ogis dan Anggun (2018) dengan judul "Hubungan Pola Makan Dengan Kejadian Penyakit Hipertensi Pada Lansia Di Dusun Blokseger Kecamatan Tegalsari Kabupaten Banyuwangi”. Penelitian ini dilaksanakan untuk mengetahui hubungaan pola makan dengan kejadian penyakit hipertensi pada lansia di Dusun Blokseger, Tegalsari, Banyuwangi. Dimana didapatkan hasil analisis menggunakan Person Chisquare menunjukan terdapat hubungan pola makan dengan kejadian hipertensi, dikarenakan $\mathrm{p}=$ Value menunjukkan hasil $\mathrm{P}=0,001$ yang artinya $\mathrm{p}$ lebih kecil dibandingkan $\alpha 0,05$ sehingga ada hubungan yang bermakna antara pola makan lansia dengan penyakit hipertensi.

\section{KESIMPULAN DAN SARAN}

\section{Kesimpulan}

1. Pola makan lansia hipertensi di Puskesmas Ubud I yang dibagi menjadi 3 (tiga) kategori yaitu, sebagian besar dari 84 responden lansia hipertensi memiliki pola makan yang cukup sebanyak 54 responden $(64,3 \%)$.

2. Derajat hipertensi pada lansia di Puskesmas Ubud I didapatkan hasil bahwa dari 84 responden sebagian besar lansia hipertensi mengalami Hipertensi Derajat I, yaitu sebanyak 47 responden $(56,0 \%)$.

3. Nilai korelasi Rank Spearman Rho menunjukan bahwa Pvalue $<0,009$ yang artinya bahwa nilai $\mathrm{p}<0,05$, maka $\mathrm{Ha}$ diterima yang mana hasilnya menunjukan ada hubungan yang signifikan antara pola makan dengan derajat hipertensi pada lansia di Puskesmas Ubud I

\section{Saran}

Diharapkan bagi peneliti yang akan meneliti tentang hipertensi disarankan untuk melakukan penelitian dengan cakupan wilayah yang luas serta jumlah sampel yang lebih banyak. Mengingat penelitian ini hanya mempergunakan satu tempat penelitian saja yaitu Puskesmas Ubud I. Kepada peneliti selanjutnya, agar hasil penelitian ini dapat dijadikan rujukan dan sumber referensi yang baru guna melanjutkan penelitian berikutnya. Peneliti selanjutnya juga sebaiknya menggunakan teknik pengumpulan data dengan lembar observasi pola makan dan lembar kuesioner yang telah diuji reliabilitas agar memperoleh hasil yang lebih valid dan akurat dalam penelitian.

\section{KEPUSTAKAAN}

Afniwati. 2019. Hubungan Antara Pola Makan Dan Kebiasaan Berolahraga Dengan Tingkat Hipertensi Pada Lansia Di Puskesmas Kutalimbaru 2019. Diperoleh tanggal 13 November 2020, dari medan.ac.id/jspui/ bitstream/123456789/2049/1/JURNAL\% 20FREEDOM.pdf

Berdamai. 2017. Berdamai Dengan Hipertensi. Jakarta: Bumi Medika

Dewi, F.S.T. 2017. Program Pencegahan Hipertensi Melalui Perubahan Pola Makan dan Peningkatan Partisipasi Dalam Kegiatan Posyandu Lansia Di Padukuhan Nglaban, Sinduharjo, Ngaglik, Sleman. Diperoleh tanggal 12 November 2020, dari http://hdss.fk.ugm.ac.id/wp content/

Jurnal Riset Kesehatan Nasional hal. 85 
http://hdss.fk.ugm.ac.id/wp content/ uploads/sites/431/2019/07/

Pemberdayaan-Masyarakat2017 Nglaban.pdf

Dinas Kesehatan Provinsi Bali (2018). Laporan tahunan dinas kesehatan tahun 2018. Bali

Harun, O. 2018. Hubungan Pola Makan Dengan Kejadian Hipertensi Pada Pasien Rawat Jalan. Diperoleh tanggal 12 November 2020, dari http:// jurnal.stikesbudiluhurcimahi.ac.id/ index.php/jkbl/article/view/66/36

Ilham, D., Harleni, H., \& Siska, R.M. 2019. Hubungan Status Gizi, Asupan Gizi Dan Riwayat Keluarga Dengan Kejadian Hipertensi Pada Lansia Di Puskesmas Lubuk Buaya Padang. Diperoleh pada 12 November 2020, dari https:// jurnal.stikesperintis.ac.id/index.php/ PSKP/article/download/334/196

Malonda, N.S.H., Lucia, K.D., \& Retno, P. 2018. Pola Makan Dan Konsumsi Alkohol Sebagai Faktor Risiko Hipertensi Pada Lansia. Diperoleh tanggal 6 Februari 2021 dari https:// jurnal.ugm.ac.id/jgki/article/ view/18219/11662

Ngurah, I.G.K.G., Ni, K.V.C.Y. 2019. Gaya Hidup Penderita Hipertensi. Diperoleh tanggal 3 Mei 2021, dari http:// poltekkes-denpasar.ac.id/files/

JURNAL\%20GEMA\%

20KEPERAWATAN/JUNI\%202015/

IGK\%20Ngurah.pdf

Pratiwi, O.G., Wibisana, A.A. 2018. Hubungan Pola Makan Dengan Kejadian Penyakit Hipertensi Pada Lansia Di Dusun Blokseger Kecamatan Tegalsari Kabupaten Banyuwangi. Diperoleh tanggal 13 November 2020, dari http:// cyber-chmk.net/ojs/index.php/ners/ article/download/785/271/

Pofil Kesehatan Kabupaten Gianyar. 2018. Laporan tahunan kabupaten gianyar tahun 2018. Bali

Situmorong, P. R. 2019. Faktor-Faktor Yang Berhubungan Dengan Kejadian Hipertensi Pada Penderita Rawat Inap Di Rumah Sakit Umum Sarii Mutiara Medan Tahun 2019. Diperoleh tanggal 14 November 2020, dari https:// www.neliti.com/id/ publications/295234/faktor-faktor-yang -berhubungan-dengan-kejadianhipertensi-pada-penderita-rawat-i

Subkhi, M. 2018. Hubungan Pola Makan Dengan Kejadian Hipertensi Pada Lansia Di Posyandu Mawar Desa Sangubanyu Kabupaten Purworejo. Diperoleh tanggal 3 Mei 2021, dari http:// digilib2.unisayogya.ac.id/ 